\title{
Effect of water-to-binder ratio and fly ash content on the mechanical and deformation properties of bendable concrete
}

\author{
Du JG ${ }^{1}$, Chen $\mathrm{B}^{2 *}$, Yang $\mathrm{YN}^{3 \#}$, Bai $\mathrm{Y}^{2}$, Wang $\mathrm{XF}^{2}$, Ao $\mathrm{J}^{3}$, Zhong $\mathrm{AR}^{1}$ and Zhang $\mathrm{DY}^{1}$ \\ ${ }^{1}$ Zhaotong Yizhao expressway project headquarters, Zhaotong, 657000, China \\ ${ }^{2}$ State Key Laboratory of Hydrology-Water Resources and Hydraulic Engineering, Nanjing Hydraulic Research Institute, Nanjing, 210029 , \\ China \\ ${ }^{3}$ Southeast University, Nanjing, 211189, China
}

\begin{abstract}
To investigate the effect of water-to-binder ratio and fly ash content on the properties of bendable concrete, we prepared four samples of different strength grades with water-to-binder ratios of 0.25 and 0.30 and fly ash contents of $60 \%$ and $80 \%$. The effects of water-to-binder ratio and fly ash content on the compressive strength, flexural strength, elastic modulus, fracture toughness, and uniaxial tensile deformation of the samples were investigated. The results show that the strength of bendable concrete can be varied by varying the water-to-binder ratio and fly ash content. Water-to-binder ratio and fly ash content showed almost the same effect on fracture toughness, whereas fly ash content exhibited a greater effect on elastic modulus. With an increase in water-to-binder ratio and fly ash content of concrete, the initial crack stress and tensile strength decreased and the ultimate tensile strain increased, but the change of water-to-binder ratio showed a more significant effect on the ultimate tensile strain.
\end{abstract}

\section{Introduction}

High-ductility cementitious composites, also known as bendable concrete, are fiber-reinforced composites with strain-hardening and multiple cracking characteristics under tensile and shear loads ${ }^{[1]}$. Since the discovery by $\mathrm{Li}^{[2,3]}$, bendable concrete has recorded much progress in terms of the preparation methods, properties, and applications. In bridge engineering, link slabs in jointless bridge decks, expansion joint, seismic node, and other special structural parts produce large deformation under applied load ${ }^{[4-6]}$. The application of bendable concrete in these special parts can greatly improve the safety and durability of the structure. Studies on the preparation technology and performance of bendable concrete in bridges are still in the initial stage and the application technology is not developed. To promote the application of bendable concrete in bridges ${ }^{[7]}$, we studied the influence of water-to-binder ratio (W/B) and fly ash (FA) content on

Table1. Physical and mechanical properties of PVA fibers

\begin{tabular}{cccccc}
\hline $\begin{array}{c}\text { Ultimate tensile } \\
\text { strength }(\mathrm{MPa})\end{array}$ & $\begin{array}{c}\text { Elastic Modulus } \\
(\mathrm{GPa})\end{array}$ & $\begin{array}{c}\text { Ultimate } \\
\text { elongation }(\%)\end{array}$ & $\begin{array}{c}\text { Equivalent } \\
\text { diameter }(\mu \mathrm{m})\end{array}$ & $\begin{array}{c}\text { Length } \\
(\mathrm{mm})\end{array}$ & $\begin{array}{c}\text { Density } \\
\left(\mathrm{g} / \mathrm{cm}^{3}\right)\end{array}$ \\
\hline$\geq 1300$ & $>35$ & $8-10$ & $>40$ & 12 & 1.3 \\
\hline
\end{tabular}

\subsection{Mix proportions}

Table 2 shows the mix proportions of the bendable concrete. 
Table2. Mix proportions of bendable Concrete

\begin{tabular}{ccccccccc}
\hline Mix number & W/B & Cement & Fly ash & Stone powder & Sand & Water & Water reducer & PVA fiber \\
\hline $\mathbf{0 . 2 5 F 6 0}$ & 0.25 & 1.00 & 1.50 & 0.18 & 0.73 & 0.63 & 0.01 & 0.05 \\
$\mathbf{0 . 2 5 F 8 0}$ & 0.25 & 1.00 & 4.00 & 0.36 & 1.45 & 1.25 & 0.01 & 0.10 \\
$\mathbf{0 . 3 F 6 0}$ & 0.30 & 1.00 & 1.50 & 0.18 & 0.73 & 0.75 & 0.00 & 0.05 \\
$\mathbf{0 . 3 F 8 0}$ & 0.30 & 1.00 & 4.00 & 0.36 & 1.45 & 1.50 & 0.01 & 0.11 \\
\hline
\end{tabular}

The mix number (in column 1) describes the W/B and mass percentage of FA in the bendable concrete; for example, $0.25 \mathrm{~F} 60$ denotes a W/B of 0.25 and $60 \%$ of cement replaced with FA.

\subsection{Test methods}

Flexural and compressive strength tests: The mechanical properties were measured using $40 \mathrm{~mm} \times 40 \mathrm{~mm} \times 160$ $\mathrm{mm}$ prism specimens, which were of 28 days old according to the "Method of testing cementDetermination of strength (ISO)" (GB/T 17671-1999).

Uniaxial tensile tests: According to the "Standard test method for the mechanical properties of ductile fiber reinforced cementitious composites (JC/T 2461-2018)," uniaxial tensile tests were conducted using dumbbellshaped specimens with a thickness of $13 \mathrm{~mm}$, parallel portion width and length of 30 and $100 \mathrm{~mm}$, respectively, and an original reference-point distance of $100 \mathrm{~mm}$. Details of the test system and process are available in Guo

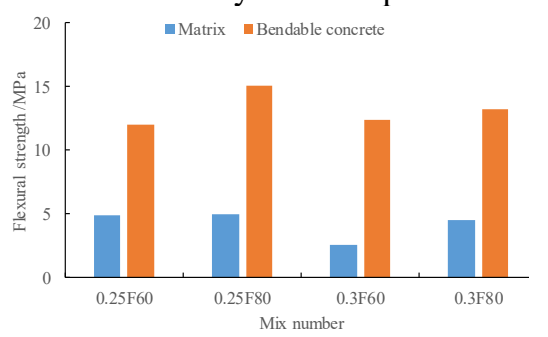

(a) Flexural strength

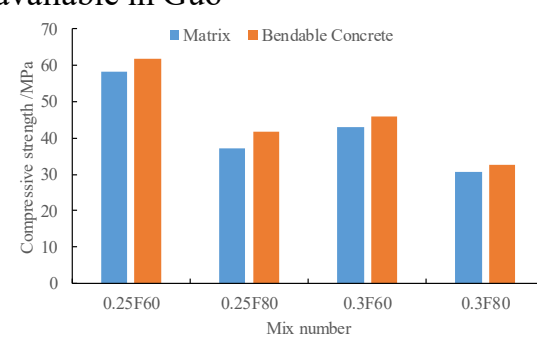

(b) Compressive strength et $\mathrm{al}^{[8,9]}$.

Fracture toughness test: According to the "Norm of fracture test of hydraulic concrete (DL/T 5332-2005)" fracture toughness tests were conducted using $40 \mathrm{~mm} \times 40$ $\mathrm{mm} \times 160 \mathrm{~mm}$ specimens. After curing the specimens to 28 days, cracks were prefabricated in the middle of the specimen span with a joint height ratio of 0.4 , joint width of 2-3 $\mathrm{mm}$, specimen span of $140 \mathrm{~mm}$, and loading speed of $0.5 \mathrm{~mm} / \mathrm{min}$. The test was conducted using MTS 810 .

\section{Results and discussion}

\subsection{Flexural strength and compressive strength}

The 28d flexural and compressive strengths of the four concrete samples were tested. The strength of the matrix and bendable concrete were measured, and the flexural-tocompressive strength ratio was calculated. The test results are shown in Fig 1.

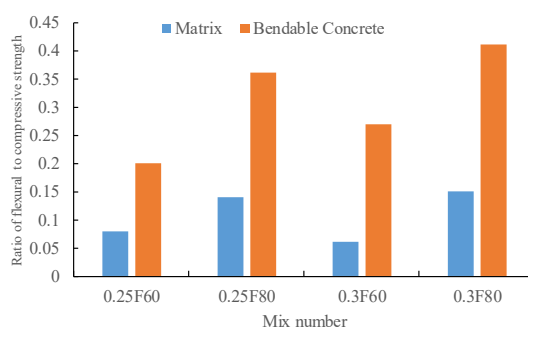

(c) Ratio of flexural-to-compressive strength

Fig.1 Flexural and compressive strengths of bendable concrete

Bendable concrete samples with different strength grades were obtained by varying the W/B and FA content. After adding PVA fiber into the matrix, the flexural strength increased by $2-3$ times, the compressive strength increased slightly by $5 \%-13 \%$, and the flexural-tocompressive strength ratio increased by $2.5-4.5$ times. These results show that the addition of PVA fiber increases the ductility of bendable concrete.

\subsection{Fracture toughness and elastic modulus}

Bendable concrete is designed based on multiscale theory. The macro properties of bendable concrete are determined by the microcosmic and mesoscopic properties, like fiber, fiber/matrix interface, and matrix properties. The fracture toughness and elastic modulus of a matrix are the mainly considered matrix properties. The two quantities can be used to calculate the fracture tip toughness $J_{\text {tip }}$ of bendable concrete, which can be used as a criterion to judge the ductility of the concrete. Therefore, it is necessary to investigate the fracture toughness and elastic modulus of the matrix.

According to DL/T 5332, the fracture toughness and elastic modulus of the four samples of bendable concrete were determined. The fracture toughness and elastic modulus of the matrix (Fig 2) were determined from the load $v s$ crack-opening displacement curves.

Fig 2 shows that at a constant W/B, an increase in the FA content decreases the fracture toughness and elastic modulus of the matrix. At W/B of 0.25 , as the FA content was increased from $60 \%$ to $80 \%$, the fracture toughness and elastic modulus of the matrix decreased by $19.7 \%$ and $37.8 \%$, respectively, and at W/B of 0.3 , they decreased by $15.2 \%$ and $31.9 \%$, respectively. Increasing W/B from 0.25 to 0.30 , the fracture toughness and elastic modulus of the matrix decreased by $7.0 \%$ to $12.5 \%$ and $12.5 \%$ to $19.9 \%$, respectively. We conclude that changes in W/B and FA content have almost the same effect on fracture toughness, whereas FA content has a greater effect on elastic modulus. 


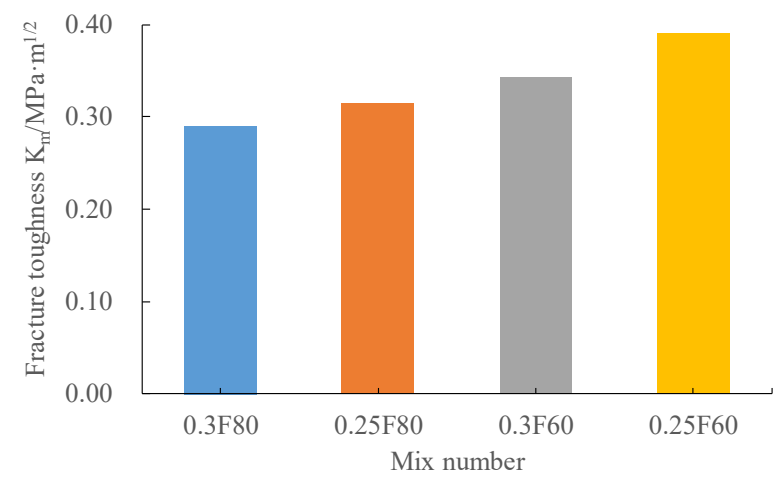

(a) Fracture toughness

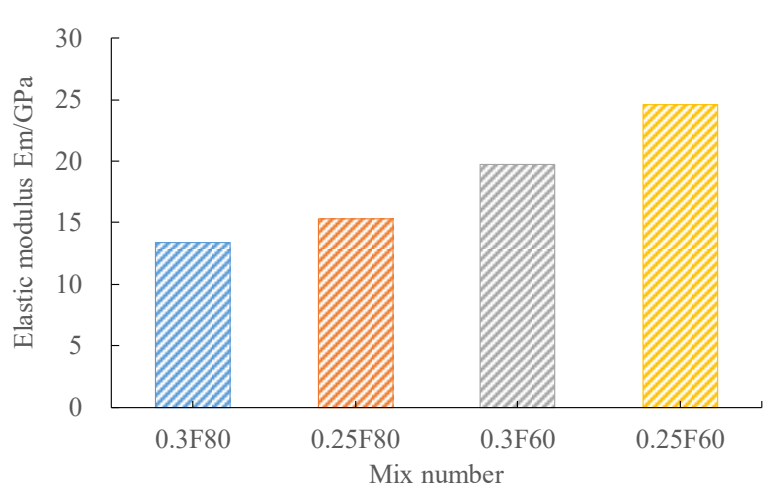

(b) Elastic modulus

Fig.2 Fracture toughness and elastic modulus of matrices

\subsection{Uniaxial tensile test}

Fig 3 shows the stress-strain curves of the four samples of bendable concrete under uniaxial tension. Under tensile loading, the material reaches the cracking strength under the action of load without failure due to strain softening, but the stress and strain continue to increase. This gives rise to the strain-hardening effect of the bendable concrete. Fig 3 shows that all four samples of bendable concrete exhibited the strain-hardening effect. After cracks occur, the stress suddenly decreases, and then increases under the fiber-bridging action. When the crack stress is reached, cracks would occur again, and the stress would be released. This process continues until the failure of the specimen occurs.

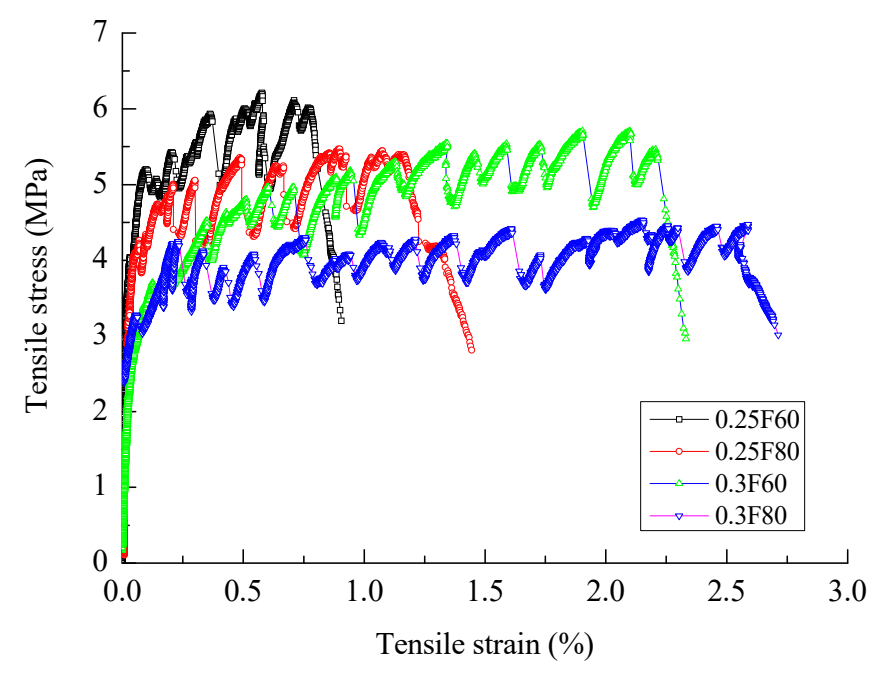

Fig.3 Uniaxial tensile stress-strain curves of bendable concrete

The initial crack stress, tensile strength, and ultimate tensile strain of the samples were obtained from the tensile

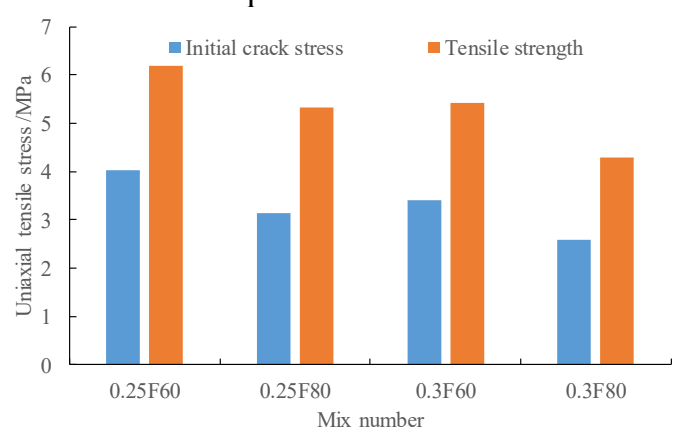

(a) Uniaxial tensile stress stress-strain curves, and are depicted in Fig 4.

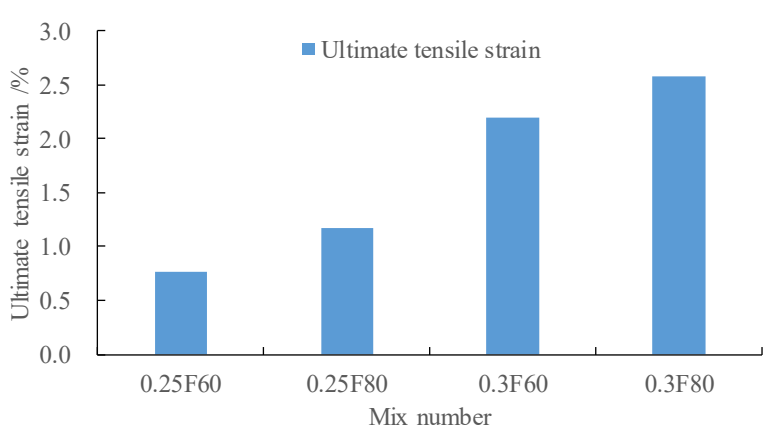

(b) Ultimate tensile strain

Fig.4 Uniaxial tensile stress and ultimate tensile strain of bendable concrete

The ultimate tensile strain of $0.3 \mathrm{~F} 80$ was the highest $(2.56 \%)$. The tensile strength decreased with the addition of FA, ranging from $14 \%$ to $26 \%$. However, the ultimate tensile strain increased with an increase in the FA content, ranging from $18 \%$ to $54 \%$. When $\mathrm{W} / \mathrm{B}$ increased from 0.25 to 0.30 , the initial crack stress and tensile strength decreased from $15.2 \%$ to $18.1 \%$ and from $12.4 \%$ to $19.5 \%$, respectively. The ultimate tensile strain increased with an increase in $\mathrm{W} / \mathrm{B}$, ranging from $120.5 \%$ to $188.2 \%$. In conclusion, an increase in FA content and $\mathrm{W} / \mathrm{B}$ of 
bendable concrete decreases the initial crack stress and tensile strength and increases the ultimate tensile strain. Additionally, the change in $\mathrm{W} / \mathrm{B}$ has a more significant effect on the ultimate tensile strain.

\section{Conclusions}

Bendable concrete with different strength grades were prepared by varying W/B and FA content.

The change in W/B and FA content have almost the same effect on fracture toughness, whereas FA content has a greater effect on elastic modulus.

With an increase in FA content and W/B of a bendable concrete, the initial crack stress and tensile strength decrease, and the ultimate tensile strain increases. However, the change in $\mathrm{W} / \mathrm{B}$ has a more significant effect on the ultimate tensile strain.

\section{Acknowledgments}

This research was financially supported by the Natural Science Foundation of Jiangsu Province (Grants No. BK20201125), Technological innovation and demonstration projects of Department of Transport of Yunnan Province (Grant No. YJKJB (2020) 62).

\section{References}

1. Li V C 2007 Progress and application of engineered cementitious composites. Journal of the Chinese Ceramic Society.35(4):531-536.

2. Li V C, Leung C.K.Y. 1992 Steady-state and multiple cracking of short random fiber composites. Journal of Engineering Mechanics.118 (11): 2246-2264.

3. Li V C 1993 From micromechanics to structural engineering-the design of cementitious composites for civil engineering application. Struct. Mech. Earthq. Eng. 10 (2):37-48.

4. Lyu B C, Ding C, Guo L P, et al 2021 Basic performances and potential research problems of strain hardening geopolymer composites: A critical review. Construction and Building Materials. 287(6): 123030.

5. Zhong J, Shen J,Wang W, et al 2019 Working state of ECC link slabs used in continuous bridge decks. Applied Sciences. 9(21):4667.

6. Gergess A N, Hawi P F 2019 Structural behavior of debonded link-slabs in continuous bridge decks. Journal of Bridge Engineering. 24(5):04019030.104019030.12 .

7. Yang Y N 2017 Multi-scale constitutive relation and design theory of ecological high ductility cementitious composites under variable temperature conditions (Nanjing: Southeast University).

8. Guo L P, Chen B, Sun W, et al 2016 Effect of expansive agent on mechanical properties and deformation behavior of HDCC. Journal of the Chinese Ceramic Society. 44(11):1609-1613.
9. Guo L P, Chen B, Wu Y, et al 2018 Effect of fiber type on the bending and uniaxial tensile properties of highstrength HDCC. Journal of Southeast University. 34(4):495-499. 